\title{
Erratum to: Function and structure of leaves contributing to increasing water storage with height in the tallest Cryptomeria japonica trees of Japan
}

\author{
Wakana Azuma $^{1} \cdot$ H. Roaki Ishii ${ }^{1}$ Katsushi Kuroda ${ }^{2} \cdot$ Keiko Kuroda $^{1}$
}

Published online: 19 December 2015

(c) Springer-Verlag Berlin Heidelberg 2015

\section{Erratum to: Trees}

\section{DOI 10.1007/s00468-015-1283-3}

Unfortunately, in the original publication of the article, the theoretical value of 'the slope of the allometric relationship between ATT and SL' under the heading "Discussion" was incorrectly published. The correct value is equal to 1.5 not 0.5 .

Also, 'mean annual temperature' under the heading "Materials and methods" was erroneously published. The correct mean annual temperature is $10.2{ }^{\circ} \mathrm{C}$ in $1981-2010$.

The online version of the original article can be found under doi: 10 . 1007/s00468-015-1283-3.

H. Roaki Ishii

hishii@alumni.washington.edu

1 Graduate School of Agricultural Science, Kobe University, 2-

411 Science and Technology Bldg., Kobe 657-8501, Japan

2 Department of Wood Properties, Forestry and Forest Products

Research Institute, 1 Matsunosato, Tsukuba,

Ibaraki 305-8687, Japan 